\title{
2.3. EVALUATION OF THE RESULTS OF A PRODUCTION SIMULATION GAME WITH DIFFERENT DEA MODELS
}

\begin{abstract}
Summary
Data Envelopment Analysis (DEA) is a method for comparing the efficiency of decisionmaking units when the output of these units is evaluated based on the amount of inputs used. A special application area of DEA is the evaluation of student groups participating in a production simulation game. This paper shows how DEA is used to compare the performance of student groups in the simulation game, and how their results can be evaluated using the efficiency scores. Several DEA models exist to capture the special characteristics of real life operation. Basic models with radial efficiency measures are used to analyse the effect of input and output weights, and to separate the proportional decrease of inputs from the independent input reduction possibilities. Slack based measure models are applied to study the joint effect of proportional and independent input/output changes. Dynamic models are used to study the change of efficiency over time. This paper compares the results of the applied models and analyses the differences. The results show that the application of an assurance regain model is strongly recommended. The presence of negative outputs requires the application of models which can be adapted to negative data. Dynamic models indicate efficiency problems even if overall performances are acceptable.
\end{abstract}

Keywords: Data Envelopment Analysis, linear programming, performance evaluation, simulation game

\section{Introduction}

Data Envelopment Analysis (DEA) is a mathematical programming approach that is used for comparing the efficiency of decision making units (DMU) such as production and/or service systems. In contrast to other methods (e.g. ratio methods) used for performance evaluation, DEA is capable of handling multiple inputs and multiple outputs as well. DEA was first introduced by Charnes, Cooper and Rhodes for evaluating nonprofit organizations. In the last few decades DEA has been extensively investigated, and it became an important research area. Several applications of DEA are reported in the literature both in the service and in the production sector as well. There is no any single DEA model which is always the best. Different application environments have generated different evaluation problems thus several variants of DEA models have been developed. In this paper DEA is applied in a higher education context to compare the performance of student groups in a production simulation game. Different DEA models are proposed to capture some special characteristics of operation. In the following part of this paper first the DEA models applied in the presented research are introduced. Next, the application environment is presented and the important differences between the suggested DEA models are discussed. Finally, conclusions are drawn and the areas of future research are summarised. 


\section{Basic concept and the applied models}

Charnes, Cooper and Rhodes (1978) suggested a linear programming model which compared DMUs using relative efficiency measures. Based on the suggested model relative efficiency analysis, or data envelopment analysis (DEA) became an important research area and a useful tool for performance evaluation. Several applications of DEA models are reported in the literature in the service and in the production sector as well (see for example Doyle and Green, 1991; Panayotis, 1992; Sherman and Ladino, 1995; Markovits-Somogyi, Gecse and Bokor, 2011). A frequently applied area of DEA is higher education. Johnes (2006) compared more than 100 higher educational institutions in England using a nested DEA model. Sinuany-Stern, Mehrez and Barboy (1994) analysed the relative efficiency of several departments within the same university.

The first model suggested by Charnes, Cooper and Rhodes (1978) can be explained by an intuitive analogy taken from engineering. According to the law of energy conservation, the different types of energies can be transformed, but energy cannot be created. In case of a power plant for example, it is not possible to produce more energy, than the energy content of the fuel used, that is, technical efficiency is always lower than 1. Applying this engineering analogy in the area of performance evaluation in operations management it can be stated, that the measure of output is always smaller than the measure of input. In the best possible case, the ratio of output measure and input measure is equal to 1 . The output and input measures are calculated as weighted outputs and weighted inputs, and the best possible weight values are looked for a DMU, which is called reference DMU $R$. Let us assume that $J$ number of DMUs are evaluated, when $K$ different outputs are observed and $I$ different inputs are used. Notations applied in this paper are listed in Table 1 . If $y_{k j}(k=1, \ldots, K ; j=1, \ldots, J)$ are the observed output values of output $k$, and $x_{i j}(i=1, \ldots, I ; j=1, \ldots, J)$ are the observed input values of input $i$ for DMU $j$, furthermore $v_{k}(k=1, \ldots, K)$ and $u_{i}(i=1, \ldots, I)$ denote the output and input weights then the linear programming formulation for finding the most favorable weights for DMU $R$ is as follows,

$$
\begin{aligned}
& \operatorname{Max}\left(\sum_{k=1}^{K} v_{k} y_{k R} / \sum_{i=1}^{I} u_{i} x_{i R}\right) \\
& \sum_{k=1}^{K} v_{k} y_{k j} / \sum_{i=1}^{I} u_{i} x_{i j} \leq 1 \quad j=1, \ldots, n \\
& u_{i}, v_{k} \geq 0 \quad i=1, \ldots, I ; \quad k=1, \ldots, K
\end{aligned}
$$

If problem (1) is transformed to eliminate the ratio of variables, and the weighted input is fixed (equal to 1) in order to get unique solution for LP problem (1), then the primal version of the input oriented, constant return to scale (CRS) model is obtained, that is, 


$$
\begin{aligned}
& \operatorname{Max}\left(\sum_{k=1}^{K} v_{k} y_{k R}\right) \\
& \sum_{i=1}^{I} u_{i} x_{i R}=1 \\
& \sum_{k=1}^{K} v_{k} y_{k j}-\sum_{i=1}^{I} u_{i} x_{i j} \leq 0 \quad j=1, \ldots, n \\
& u_{i}, v_{k} \geq 0 \quad i=1, \ldots, I ; \quad k=1, \ldots, K
\end{aligned}
$$

Table 1: Notation (1) - Indices and parameters

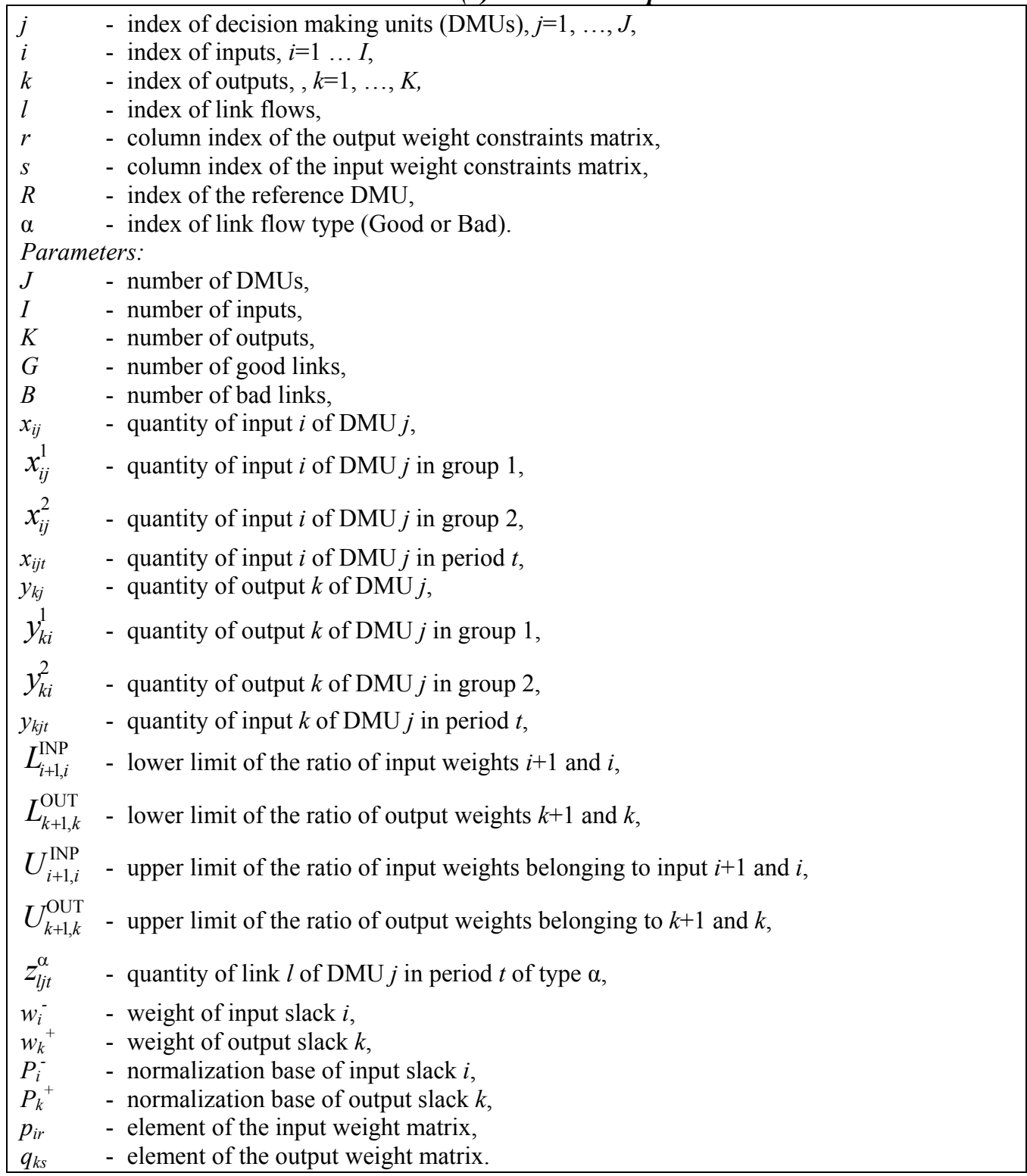


Table 2: Notation (2) - Variables

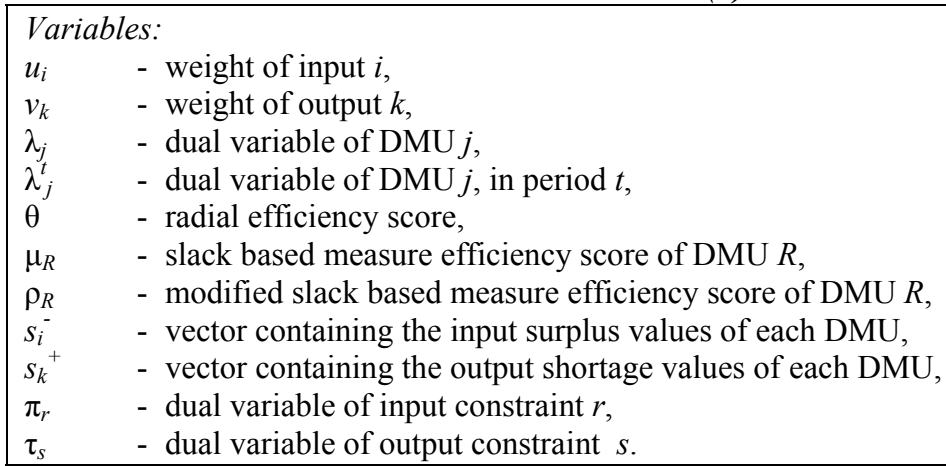

The dual version of problem (2), however, has more practical relevance and leads to another interpretation of DEA. According to the dual interpretation any linear combination of the observed output and input values leads to a new and feasible DMU, which may exist in practice. The production possibility set is determined by all possible linear combinations of the observed outputs and inputs. If $\lambda_{j}(j=1, \ldots, J)$ are the coefficients of the linear combination of output and input values, then the production possibility set of DMU $R$ can be defined as follows,

$$
\begin{array}{rl}
y_{k R} \leq \sum_{j=1}^{J} y_{k j} \lambda_{j} & k=1, \ldots, K \\
x_{i R} \geq \sum_{j=1}^{J} x_{i j} \lambda_{j} & i=1, \ldots, I
\end{array}
$$

If we consider the $\lambda_{j}(j=1, \ldots, J)$ coefficients as variables, and a proper objective function is used to get an optimal combination of the output and input values, then the distance from any existing DMU from the optimal DMUs can be a basis of an efficiency score. The dual version of the input oriented CRS model assumes that all inputs must be decreased to the same proportion $(\theta)$, and efficiency is given by the smallest proportion. Consequently the smallest amount of input necessary to produce the observed output must be determined. The corresponding dual LP model is as follows,

$$
\begin{array}{ll}
\operatorname{Min}(\theta) & k=1, \ldots, K \\
\sum_{j=1}^{J} \lambda_{j} y_{k j} \geq y_{k R} & i=1, \ldots, I \\
\sum_{j=1}^{J} \lambda_{j} x_{i j} \leq \theta x_{i R} & j=1, \ldots, J \\
\lambda_{j} \geq 0 &
\end{array}
$$

In primal problem (2), the optimal value of the weights of inputs and outputs are determined by linear programming. Frequently, the value of some weights is zero, that is, when the efficiency score is calculated, some inputs and outputs have zero weights. Inputs and outputs with zero weights are ignored in the evaluation, which is not always 
acceptable for management purposes. To avoid the problem of zero weights, restrictions which reflect the intention of management can be added to model (2). One possible form of weight restriction is when constraints for all possible pairs of inputs and outputs are introduced, that is,

$$
\begin{array}{ll}
L_{k, k+1}^{\mathrm{OUT}} \leq \frac{v_{k+1}}{v_{k}} \leq U_{k, k+1}^{\mathrm{OUT}} & k=1, \ldots K-1 \\
L_{i, i+1}^{\mathrm{INP}} \leq \frac{u_{i+1}}{u_{i}} \leq U_{i, i+1}^{\mathrm{INP}} & i=1, \ldots I-1
\end{array}
$$

Adding constraints (5) to model (2) and writing the dual form of the resulting model, the input oriented CRS assurance region (AR) dual model is obtained which is as follows,

$$
\begin{array}{ll}
\operatorname{Min}(\theta) & \\
\sum_{j=1}^{J} \lambda_{j} y_{k j}+\sum_{S} \tau_{s} q_{k s} \geq y_{k R} & k=1, \ldots, K \\
\sum_{j=1}^{J} \lambda_{j} x_{i j}-\sum_{r} \pi_{r} p_{i r} \leq \theta x_{i R} & i=1, \ldots, I \\
\lambda_{j}, \tau_{s}, \pi_{r} \geq 0 & j=1, \ldots, J ; \quad \forall s ; \quad \forall r
\end{array}
$$

In model (2), (4) and (6) input and output data can only be semi-positive. In practice, however, sometimes negative inputs and outputs may frequently occur. Several attempts can be found in the literature to cope with negative data when radial efficiency measure is used. In the following part of the paper we use the semi-oriented radial model (SORM) proposed by Emrouznejad, Anouze and Thanassoulis (2010). In the SORM model all inputs and outputs are separated into two groups. Positive data belong to group 1 and the absolute values of the negative data belong to group 2 . The separated input data of the SORM model are as follows,

$$
\begin{aligned}
& x_{i j}^{(1)}= \begin{cases}x_{i j} & \text { if } x_{i j} \geq 0 \\
0 & \text { if } x_{i j}<0\end{cases} \\
& x_{i j}^{(2)}= \begin{cases}0 & \text { if } x_{i j} \geq 0 \\
a b s\left(x_{i j}\right) & \text { if } x_{i j}<0\end{cases}
\end{aligned}
$$

and the separated output data of the SORM model are as follows,

$$
\begin{aligned}
& y_{k j}^{(1)}=\left\{\begin{array}{l}
y_{k j} \text { if } y_{k j} \geq 0 \\
0 \quad \text { if } y_{k j}<0
\end{array}\right. \\
& y_{k j}^{(2)}=\left\{\begin{array}{l}
0 \text { if } y_{k j} \geq 0 \\
a b s\left(y_{k j}\right) \text { if } y_{k j}<0
\end{array}\right.
\end{aligned}
$$


Positive outputs and negative inputs are favorable for the decision maker. Consequently, the ideal DMU is always constrained by these values from below, that is, the production possibility set determined by the positive outputs and negative inputs are as follows,

$$
\begin{aligned}
& y_{k R}^{(1)} \leq \sum_{j=1}^{J} y_{k j}^{1} \lambda_{j} \quad k=1, \ldots, K \\
& x_{i R}^{(2)} \leq \sum_{j=1}^{J} x_{i j}^{2} \lambda_{j} \quad i=1, \ldots, I
\end{aligned}
$$

Negative outputs and positive inputs are unfavourable for the decision maker. Consequently, the ideal DMU is always constrained by these values from above, that is, the production possibility set determined by the negative outputs and positive inputs are as follows,

$$
\begin{array}{rl}
y_{k R}^{(2)} \geq \sum_{j=1}^{J} y_{k j}^{2} \lambda_{j} & k=1, \ldots, K \\
x_{i R}^{(1)} \geq \sum_{j=1}^{J} x_{i j}^{1} \lambda_{j} & i=1, \ldots, I
\end{array}
$$

Based on constraints (9) and (10), the dual form of the SORM model is as follows,

$$
\begin{aligned}
& \operatorname{Min}(\theta) \\
& \sum_{j=1}^{J} y_{k j}^{1} \lambda_{j} \geq y_{k R}^{1} \quad k=1, \ldots, K \\
& \sum_{j=1}^{J} y_{k j}^{2} \lambda_{j} \leq y_{k R}^{2} \quad k=1, \ldots, K \\
& \sum_{j=1}^{J} x_{i j}^{1} \lambda_{j} \leq \theta x_{i R}^{1} \quad i=1, \ldots, I \\
& \sum_{j=1}^{J} x_{i j}^{2} \lambda_{j} \geq \theta x_{i R}^{2} \quad i=1, \ldots, I \\
& \lambda_{j} \geq 0 \quad j=1, \ldots, J
\end{aligned}
$$

Models (2), (4), (6) and (11) are based on a radial measure of efficiency, that is, all inputs are decreased proportionally by the same ratio. The slack based model (SBM) proposed by Tone (1999) uses the difference of the observed values and the best possible linear combination of inputs and outputs. The difference of the actual value and the best possible value is called slack. With the help of production possibility set (3), all possible slack values of DMU $R$ are given by (12) if $s_{k}{ }^{+}$indicate the output increase possibility of output $k$ and $s_{i}{ }^{-}$indicate the input decrease possibility of input $i$, that is,

$$
\begin{array}{ll}
s_{k}^{+}=\sum_{j=1}^{J} \lambda_{j} y_{k j}-y_{k R} & k=1, \ldots, K \\
s_{i}^{-}=x_{i R}-\sum_{j=1}^{J} \lambda_{j} x_{i j} & i=1, \ldots, I
\end{array}
$$


The slack values express the distance of a DMU from the best possible DMU. Based on the slack values the following efficiency measure can be used,

$$
\mu_{R}=\frac{1-\sum_{i=1}^{I} w_{i}^{-} s_{i}^{-} / x_{i R}^{-}}{1+\sum_{k=1}^{K} w_{k}^{+} s_{k}^{+} / y_{k R}^{+}}
$$

The slack based measure of efficiency proposed by Tone (1999) can take any value between 0 and 1 , and it is based on the weighted average of the normalized input and output slacks. The basis of normalization is the actual value of outputs and inputs in expression (13).

The basic DEA concept assumes that all observed inputs and outputs are semi-positive. In case of negative values some modification of the formulation is required to get feasible solution and to keep the efficiency score between 0 and 1. Silva Portela, Thanassoulis and Simpson (2004) proposed a directional distance approach which is based on the range of the possible output and input improvements. Assume that the highest possible output is the highest observed output, and the improvement possibility is defined by the distance between the highest possible value and the observed value. In this case, the output slack may change in the following range for reference DMU $R$,

$$
P_{k R}^{+}=\max _{j}\left(y_{k j}\right)-y_{k R} \quad k=1 \ldots, K
$$

Similarly, assume, that the smallest possible input is the smallest observed input, and the improvement possibility is defined by the distance between the observed value and the smallest possible value. In this case, the input slack may change in the following range for reference DMU $R$,

$$
P_{i R}^{-}=x_{i R}-\min _{j}\left(x_{i j}\right) \quad i=1 \ldots, s
$$

Ranges (14) and (15) are called Silver-Portela (S-P) ranges, and can be used for normalizing the slack values in case of negative outputs and/or inputs. Correspondingly, the modified slack based model (MSBM) proposed by Sharp, Meng and Liu (2007) applies the following efficiency measure,

$$
\rho_{R}=\frac{1-\sum_{i=1}^{I} w_{i} s_{i}^{-} / P_{i R}^{-}}{1+\sum_{k=1}^{K} w_{k} s_{k}^{+} / P_{k R}^{+}}
$$

Solving models (4), (6) and (11) in the first phase, a second phase is required. In the second phase a slack maximization model is solved using the optimal efficiency score of phase 1. Phase 2 is used to check the strong efficiency conditions, and to obtain the independent input decrease and output increase possibilities (Cooper, Seiford and Tone, 2007). In case of the slack based models, this second phase is not required.

Several variations of the radial and slack based models exist in the literature (see for example Sooper, Seiford and Tone, 2007). Depending on the main objective of evaluation, input oriented, output oriented or non-oriented models can be used. If the rate of the use of inputs and the rate of the generation of outputs change, then a 
variable return to scale (VRS) model is appropriate. If information related to input and output weights are necessary, then primal models are preferred. Assurance region models can be used when weight restrictions are introduced by the decision maker. Finally, when the efficiency of several DMUs must be evaluated, and the inputs and outputs of these DMUs are not independent from each other, then network DEA models are recommended (Tone and Tsutsui, 2010).

Dynamic DEA models are special network DEA models. In this case, the performance of the same DMU must be evaluated over several periods; consequently, the production possibility set must be defined for each period. A part of the production possibility set is determined by the observed output and input values of the DMUs in each period $t$, that is, constraints (2) must be completed with index $t$, as follows,

$$
\begin{array}{ll}
y_{k R t} \leq \sum_{j=1}^{J} y_{k j t} \lambda_{j}^{t} & k=1, \ldots, K ; \quad t=1, \ldots, T \\
x_{i R t} \geq \sum_{j=1}^{J} x_{i j t} \lambda_{j}^{t} & i=1, \ldots, I ; \quad t=1, \ldots, T
\end{array}
$$

In dynamic models, the production possibility set of a given period is also determined by the link flows $\left(z_{l j t}\right)$ which connect the neighbouring periods. If a link flow has favourable effect on operation, then it is called "Good" link (Tone and Tsutsui, 2010) and an output type constraints must be determined, that is,

$$
\sum_{j=1}^{J} z_{l j t}^{\text {Good }} \lambda_{j}^{t} \geq z_{R t}^{\text {Good }} \quad l=1, \ldots, G ; \quad t=1, \ldots, T
$$

If a link flow has unfavourable effect on operation, then it is called "Bad" link (Tone and Tsutsui, 2010) and an input type constraints must be determined, that is,

$$
\sum_{j=1}^{J} z_{l j t}^{\mathrm{Bad}} \lambda_{j}^{t} \leq z_{R t}^{\mathrm{Bad}} \quad l=1, \ldots, B ; \quad t=1, \ldots, T
$$

The different periods are connected by the continuity equations in the dynamic models. The optimal linear combination of the link flows is identical in the neighbouring periods, that is,

$$
\sum_{l} z_{l j t}^{\alpha} \lambda_{j}^{t}=\sum_{l} z_{l j t}^{\alpha} \lambda_{j}^{t+1} \quad t=1, \ldots, T-1 ; \quad \alpha=\{\text { Good, Bad }\}
$$

In the following part of the paper the performance of the student groups in the production simulation games are evaluated with several DEA models. Radial efficiency is determined with model (4), (6) and (11). Slack based efficiency is determined with objective functions (13) and (16). Finally, dynamic efficiency is determined using constraints (17), (18), (19) and (20).

\section{Application environment}

We analysed a production simulation game, which is developed by Ecosim to support education and training in the production management area (www.ecosim.hu). The objective of the game is to simulate production management decision making in a car 
engine manufacturing factory. The factory produces three different car engines for five different markets in 7 periods. Each market has its own demand characteristics. The car engines are assembled from parts on assembly lines operated by workers.

For the next production period (year) each student group must make sales and marketing, production, investment and financial decisions. After submitting the decisions, the simulation program generates the results of the actual production period. The results are summarized in a production report and in a financial report. Using the results and experiences of the earlier periods the student groups try to increase operational performance of the next periods.

We used different input oriented DEA models for evaluating the performance of student groups at the end of the seventh period of the simulation game. In all cases we applied a constant return to scale model, because there is not size difference between the DMUs, thus a variable return to scale (VRS) approach is not relevant.

Two outputs and four inputs were considered in the analysis. In our previous papers we presented the evaluation of the performance of student groups using different outputs (Koltai and Uzonyi 2012). In this paper, the results of several DEA models addressing various modelling problems are presented. One of the outputs is cumulated production quantity which reflects the effect of production management decisions related to machine and worker capacity, to material requirement planning and to inventory management. The other output is net profit which integrates the effect of marketing, production and financial decisions. The four inputs - cumulated number of workers, cumulated number of machine hours, cumulated sum of money spent on raw materials and cumulated value of credits - represent the resources used in the production process. Consequently, the performance of the production system based on these decisions reflects student's knowledge in the related areas.

\section{Comparison of the results of the different DEA models}

The performance of 18 student groups is compared using input oriented CRS, CRSAR, SORM, SBM, MSBM and dynamic MSBM model. The results are summarized in Table 2. Column 2 and 3 shows the values of the two outputs applied in the evaluation. These data are properly scaled to avoid numerical problems. Column 4-9 shows the efficiency scores of the different models. In those models, which cannot handle negative data, negative values were substituted by zero.

Using the basic input oriented CRS model, 7 student groups have the highest possible efficiency score. The results show that the operation of almost half of the DMUs is efficient. Furthermore, the value of the efficiency score of inefficient groups is close to 1 , which indicate a low discrimination power of the model. In this case, a large number of input and output weights are zero, consequently, for example, the profit has insignificant effect on the obtained efficiency scores.

Applying weight restrictions (CCR-AR), it can be observed that all groups obtained lower scores. The number of the efficient groups is also reduced, only groups 3,7 and 15 remained efficient. We applied 0.1 for the pairwise relative lower limit of the inputs, and 0.25 for the lower limit of the ratio of outputs. 
Table 2: Efficiency results of DEA models

\begin{tabular}{|c|c|c|c|c|c|c|c|c|}
\hline Team & $\begin{array}{c}\text { Output 1 } \\
\text { Net } \\
\text { profit }\end{array}$ & $\begin{array}{c}\text { Output 2 } \\
\text { Production } \\
\text { Quantity }\end{array}$ & $\mathbf{C R S}$ & $\begin{array}{c}\text { CRS- } \\
\text { AR }\end{array}$ & SORM & SBM & MSBM & $\begin{array}{c}\text { Dyna- } \\
\text { mic } \\
\text { MSBM }\end{array}$ \\
\hline $\mathbf{1}$ & 0,650 & 2,701 & $\mathbf{1 , 0 0 0 0}$ & 0,9281 & $\mathbf{1 , 0 0 0 0}$ & $\mathbf{1 , 0 0 0 0 0}$ & $\mathbf{1 , 0 0 0 0}$ & 0,6141 \\
\hline $\mathbf{2}$ & 0,097 & 2,714 & $\mathbf{1 , 0 0 0 0}$ & 0,8109 & $\mathbf{1 , 0 0 0 0}$ & $\mathbf{1 , 0 0 0 0 0}$ & $\mathbf{1 , 0 0 0 0}$ & 0,5409 \\
\hline $\mathbf{3}$ & 1,874 & 2,911 & $\mathbf{1 , 0 0 0 0}$ & $\mathbf{1 , 0 0 0 0}$ & $\mathbf{1 , 0 0 0 0}$ & $\mathbf{1 , 0 0 0 0 0}$ & $\mathbf{1 , 0 0 0 0}$ & 0,9017 \\
\hline $\mathbf{4}$ & 0,186 & 2,448 & 0,9732 & 0,8750 & 0,9732 & 0,22036 & 0,7033 & 0,5603 \\
\hline $\mathbf{5}$ & $-0,269$ & 2,327 & 0,9579 & 0,7583 & 0,9579 & $\mathbf{1 , 0 0 0 0 0}$ & 0,5192 & 0,5701 \\
\hline $\mathbf{6}$ & 0,046 & 2,573 & 0,9823 & 0,8583 & 0,9823 & 0,07051 & 0,6846 & 0,5242 \\
\hline $\mathbf{7}$ & 1,656 & 2,778 & $\mathbf{1 , 0 0 0 0}$ & $\mathbf{1 , 0 0 0 0}$ & $\mathbf{1 , 0 0 0 0}$ & $\mathbf{1 , 0 0 0 0 0}$ & $\mathbf{1 , 0 0 0 0}$ & $\mathbf{1 , 0 0 0 0}$ \\
\hline $\boldsymbol{8}$ & 1,007 & 2,553 & 0,9917 & 0,9152 & 0,9917 & 0,62730 & 0,6043 & 0,8186 \\
\hline $\mathbf{9}$ & 1,714 & 2,977 & $\mathbf{1 , 0 0 0 0}$ & 0,9999 & $\mathbf{1 , 0 0 0 0}$ & $\mathbf{1 , 0 0 0 0 0}$ & $\mathbf{1 , 0 0 0 0}$ & 0,7370 \\
\hline $\mathbf{1 0}$ & 1,051 & 2,836 & 0,9982 & 0,9351 & 0,9982 & 0,88190 & 0,8757 & 0,6030 \\
\hline $\mathbf{1 1}$ & 0,987 & 2,440 & 0,9982 & 0,9473 & 0,9982 & 0,75962 & 0,7461 & 0,6316 \\
\hline $\mathbf{1 2}$ & 0,183 & 2,466 & 0,9798 & 0,8647 & 0,9798 & 0,19680 & 0,6468 & 0,5510 \\
\hline $\mathbf{1 3}$ & 0,675 & 2,368 & 0,9322 & 0,8020 & 0,9322 & 0,47361 & 0,5573 & 0,5265 \\
\hline $\mathbf{1 4}$ & 1,729 & 2,650 & $\mathbf{1 , 0 0 0 0}$ & 0,9859 & $\mathbf{1 , 0 0 0 0}$ & $\mathbf{1 , 0 0 0 0 0}$ & $\mathbf{1 , 0 0 0 0}$ & $\mathbf{1 , 0 0 0 0}$ \\
\hline $\mathbf{1 5}$ & 0,879 & 2,665 & $\mathbf{1 , 0 0 0 0}$ & $\mathbf{1 , 0 0 0 0}$ & $\mathbf{1 , 0 0 0 0}$ & $\mathbf{1 , 0 0 0 0 0}$ & $\mathbf{1 , 0 0 0 0}$ & 0,7633 \\
\hline $\mathbf{1 6}$ & 0,197 & 2,487 & 0,9508 & 0,8305 & 0,9508 & 0,18356 & 0,5641 & 0,5515 \\
\hline $\mathbf{1 7}$ & 0,667 & 2,964 & 0,9053 & 0,8250 & 0,9053 & 0,42232 & 0,0676 & 0,5696 \\
\hline $\mathbf{1 8}$ & 0,799 & 2,553 & 0,9867 & 0,8731 & 0,9867 & 0,69966 & 0,7184 & 0,5614 \\
\hline
\end{tabular}

It is proved, that the efficiency score of the SBM models is not greater than the CRS efficiency values (Tone, 1999). In addition, a DMU is CCR efficient if it is SBM efficient. Consequently, CCR efficient student groups remained at the efficient status under SBM evaluation. The SBM score of most of the inefficient groups are lower than the CRS scores. Group 5 has higher efficiency score with SBM than with CRS evaluation. This contradiction indicates that the SBM model can not be applied in this case. Note, that group 5 has negative net profit, consequently the output values are not semi-positive, and the efficiency scores are theoretically erroneous. We can also observe large differences between the efficiency scores of the CRS (CRS-AR) and the SBM models. These large differences can be explained by the fact, that slacks are not reflected in the CRS scores. The CRS model calculate the slack values in the second phase, and these values are considered, when the target quantities are calculated, but are not reflected in the scores.

Finally, the last column shows the overall efficiency scores calculated by the dynamic MSBM model. The results show, that only groups 7 and 14 remained efficient. Moreover the efficiency scores of most of the groups are significantly reduced. A detailed analysis of the period efficiencies showed, that some groups which have good overall performance, may have efficiency problems in some periods.

The MSBM and the SORM models can be used to handle negative data. According to Table 2. MSBM and SORM selected the same DMUs as efficient, but different target values are recommended. The target values recommended by the CRS, and the MSBM models for a selected student group (Team 10) is presented in Table 3. It can be seen, 
that the MSBM target values indicate a slightly smaller input reduction, than that of the CRS values, but with a higher production quantity.

Table 3: Target values of Team 10

\begin{tabular}{|l|c|c|c|c|c|c|}
\hline & $\begin{array}{c}\text { Production } \\
\text { quantity }\end{array}$ & $\begin{array}{c}\text { Net } \\
\text { profit }\end{array}$ & $\begin{array}{c}\text { No. } \\
\text { workers }\end{array}$ & $\begin{array}{c}\text { Machine } \\
\text { hours }\end{array}$ & $\begin{array}{c}\text { Raw } \\
\text { materials }\end{array}$ & Debt \\
\hline Original & 2836320 & 1050699 & 13662 & 3284436 & 5608796 & 1632000 \\
\hline CRS & 2836320 & 1050699 & 12489 & 3278483 & 5410413 & 1123659 \\
\hline MSBM & 2841860 & 1050699 & 12514 & 3284436 & 5423519 & 1124375 \\
\hline
\end{tabular}

Source: the authors own table

Note, that the SORM efficiency scores are identical with the CRS efficiency scores in Table 1 . This can be explained by the fact, that Team 5 is the only team with negative output value. In this special case, the constraint belonging to this unfavorable output does not influence the production possibility set, and consequently the efficiency scores.

\section{Conclusion}

This paper compared the results of different DEA models when the performance of student groups in a production simulation game is evaluated. Basic models with radial efficiency measures are used to analyse the effect of input and output weights, and to separate the proportional decrease of inputs from the independent input reduction possibilities. Slack based measure models are applied to study the joint effect of proportional and independent input/output changes. The results show the advantage of the application of the assurance regain model. The presence of negative outputs requires the application of models which can be adapted to negative data.

The evaluation of the groups in the static DEA models uses aggregated input and output values. The inputs and outputs in the 7 production periods are simply cumulated, consequently, the dynamic behaviour of the groups is not reflected in the results. When applying Dynamic DEA models, the progress of groups during the decision making process can be analysed and a more detailed picture about the learning process can be obtained. (Koltai and Uzonyi 2013) Analysing the different results provided by the static and dynamic models and using the information provided by the dynamic models about local efficiency problems are an interesting and promising topic for further research.

\section{References}

1. Charnes, A., Cooper, W.W., Rhodes, A. (1978): Measuring the efficiency of decision making units. "European Journal of Operations Research", 2, pp. 429-444. http://dx.doi.org/10.1016/0377-2217(79)90229-7

2. Cooper, W.W., Seiford, L.M., Tone, K. (2007): Data envelopment analysis. Springer. http://dx.doi.org/10.1007/978-0-387-45283-8

3. Doyle, J.R. and Green, R.H. (1991): Comparing products using data envelopment analysis. “Omega International Journal of Management Sciences", 19(6), pp. 631-638. http://dx.doi.org/10.1016/0305-0483(91)90012-i 
4. Emrouznejad, A., Anouze, A.L., Thanassoulis, E. (2010): A semi - oriented radial measure for measuring the efficiency of decision making units with negative data, using DEA. "European Journal of Operational Research", 200, pp. 297-304. http://dx.doi.org/10.1016/j.ejor.2009.01.001

5. Johnes, J., (2006): Data envelopment analysis and its application to the measurement of efficiency in higher education. "Economics of Education Review", 25(3), pp. 273-288. http://dx.doi.org/10.1016/j.econedurev.2005.02.005

6. Koltai, T., Uzonyi-Kecskés, J. (2012): Data Envelopment Analysis and its Application for Measuring the Performance of Students in a Production Simulation Game. In: Illés, Cs.B. (ED) SMEs' Management in the 21st Century: Challanges and Solutions. Czestochowa: Publishing Section of the Faculty of Management, Czestochova University of Technology, pp. 322-335.

7. Koltai, T., Uzonyi-Kecskés, J. (2013): Analysis of the learning process in a production simulation game with DEA using cumulative data. In: Miskolci Egyetem. Innovációs és Technológia Transzfer Centrum (szerk.). microCAD 2013: XXVII. microCAD International Scientific Conference: Section Q: Economic Challenges in the 21st Century (Gazdasági kihívások a XXI. században). Miskolci Egyetem, Paper Q9. 6 p.

8. Markovits-Somogyi. R., Gecse, G. and Bokor, Z. (2011): Basic efficiency measurement of Hungarian logistics centres using data envelopment analysis. "Periodica Polytechnica Social and Management Sciences", 19(2), pp. 97-101.

http://dx.doi.org/10.3311/pp.so.2011-2.06

9. Panayotis, A.M. (1992): Data envelopment analysis applied to electricity distribution districts. "Journal of the Operations Research Society", 43(5), pp. 549-555. http://dx.doi.org/10.1057/jors.1992.80

10. Sharp, J., Meng, W., Liu, S. (2006): A modified slacks based measure model for data envelopment analysis with 'natural' negative outputs and inputs. "Journal of Operational Research Society" 57(11), pp. 1-6. http://dx.doi.org/10.1057/palgrave.jors.2602318

11. Sherman, H.D. and Ladino G. (1995): Managing bank productivity using data envelopment analysis (DEA). "Interfaces", 25(2), pp. 60-73. http://dx.doi.org/10.1287/inte.25.2.60

12. Sinuany-Stern, Z., Mehrez, A. and Barboy, A. (1994): Academic departments efficiency via DEA. "Computers \& Operations Research", 21(5), pp. 543-556. http://dx.doi.org/10.1016/0305-0548(94)90103-1

13. Tone, K. (1999): A slacks - based measure of efficiency in data envelopment analysis. "European Journal of Operational Research", 130 pp. 498-509. http://dx.doi.org/10.1016/s0377-2217(99)00407-5

14. Tone, K. and Tsutsui, M. (2010): Dynamic DEA: A slack-based measure approach. "Omega", 38, pp. 145-156. http://dx.doi.org/10.1016/j.omega.2009.07.003

15. Silva Portela, M.C.A., Thanassoulis, E., Simpson, G. (2004): Negative Data in DEA: a directional distance approach applied to bank branches. "Journal of Operational Research Society”, 55, pp. 1111-1121. http://dx.doi.org/10.1057/palgrave.jors.2601768 